\title{
THE MICROMETEOROID IN THE UPPER ATMOSPHERE
}

\author{
F. KAMI JO \\ Department of Astronomy \\ University of Tokyo \\ Bunkyo-ku, Tokyo 113 \\ Japan
}

ABSTRACT. The temperature and the radius variation of micrometeoroids in the thermosphere and the mesosphere are calculated theoretically. If the radius and the initial velocity are $100 \mu \mathrm{m}$ and $30 \mathrm{~km} / \mathrm{sec} \mathrm{re}^{-}$ spectively, the evaporation height and the velocity coincide almost exactly with those of the Capricornids and the Virginids from the meteor stream observation.

Moreover, it is shown that the not evaporated debris till the end of the sublimation may become spherules in the bottom of deep sea; and that fluffy micrometeoroids $(10 \mu \mathrm{m}$ size) floating in the stratosphere are also consistent with our calculation.

The recondensation and the coagulation of the evaporated gas molecules from the meteoroid are also calculated, and it is shown that these secondary particles are very small and few.

1. Int roduction

There are two kinds of small meteorites.

1) The spherules which are found in the bottom of the deep sea Their shape is spherical and the typical size is about $100 \mu \mathrm{m}$.

2) The micrometeoroids which are collected in the stratosphere by airplane. Their shape is not spherical and its typical character is that it is fluffy. The typical size is about $10 \mu \mathrm{m}$.

We calculate the origin of these two types by a simple model.

2. The Method of Calculation

The assumptions of the calculation are:

1) The kinetic energy of the atmospheric molecules which collide the meteorite is converted entirely to heat up the collided meteorite.

2) The absorbed heat is changed to the elevation of temperature and the radiation loss (Stefan-Boltzmann) of the meteorite.

3) If the temperature of the meteorite becomes higher than the sublimation temperature, the absorbed heat is changed to the evapo-

A.C. Levasseur-Regourd and H. Hasegawa (eds.), Origin and Evolution of Interplanetary Dust, 303-306. (1) 1991 Kluwer Academic Publishers, Printed in Japan. 
ration heat and the radiation loss, while the temperature of the meteorite becomes constant.

\section{The Result of Calculation}

Three examples are plotted in Fig. 1. The upper three curves are the variation of temperature (abscissa) of three meteorites against the hight from the ground level (ordinate). The initial velocity $v$ and the initial radius $\mathrm{r}$ are $\mathrm{v}=30 \mathrm{~km} / \mathrm{sec}, \quad \mathrm{r}=10 \mu \mathrm{m} ; 30 \mathrm{~km} / \mathrm{sec}, 100 \mu \mathrm{m}$; and $20 \mathrm{~km} / \mathrm{sec}, 100 \mu \mathrm{m}$; respectively.

The most typical case $(30 \mathrm{~km} / \mathrm{sec}, 100 \mu \mathrm{m})$ is shown as the second curve. The temperature begins to become gradually higher at the height of $120 \mathrm{~km}$ and reaches the sublimation temperature at $97.2 \mathrm{~km}$.

After this point variation of the radius in percent of the initial radius (abscissa) is plotted against the height (ordinate) in the left lower part of Fig. 1.

Physical constants are assumed, corresponding to silicates, as follows: specific heat $C=10^{7} \mathrm{erg} / \mathrm{K} / \mathrm{g}$, sublimation heat $\mathrm{L}=6 * 10^{10} \mathrm{erg}$ $/ \mathrm{g}$ and sublimation temperature is $2100 \mathrm{~K}$.

To explain the left-lower part of $\mathrm{Fig.1}$, which is rather complicated, we take as an example $30 \mathrm{~km} / \mathrm{sec}, 100 \mu \mathrm{m}$ particle. As mentioned above, the temperature becomes high enough to reach the sublimation temperature at $Z=97.2 \mathrm{~km}$. From this point, the heat obtained by the collision with the atmospheric gas molecules is converted into sublimation heat and temperature becomes constant. The radius becomes smaller and smaller by evaporation. It is plotted in the second curve of the left-lower part of Fig. 1.

Namely, $100 \%(\mathrm{r}=100 \mu \mathrm{m})$ at $\mathrm{Z}=97.2 \mathrm{~km}$, $50 \%(\mathrm{r}=50 \mu \mathrm{m})$ at $\mathrm{Z}=86.2 \mathrm{~km}$.

The radiation loss becomes gradually larger, compared with the sublimation loss, and at last at $\mathrm{Z}=81.3 \mathrm{~km}$, where $\mathrm{r}=8.3 \mu \mathrm{m}$, the radiation loss is large enough to be equal to the energy gain. Thus the sublimation stops there.

In other words, the meteorite is observed as a meteor at $97.2 \mathrm{~km}>$ $\mathrm{Z}>81.3 \mathrm{~km}$ and radius of the debris : $\mathrm{r}=8.3 \mu \mathrm{m}$.

Two other cases are also plotted as the first and the third curves in Fig. 1, and final $\mathrm{r}=4.0 \mu \mathrm{m}$ and $24 \mu \mathrm{m}$, respectively.

\section{Secondary Particle}

"Secondary particle" means the recondensation of the evaporated vapour. As the surrounding temperature is very low, the evaporated vapour condenses into grains soon after the evaporation.

We have calculated several cases, but to avoid to integrate the complicated equation of coagulation numerically, we adopt "similarity solution" (Onaka et al. 1978).

The result of an example $(30 \mathrm{~km} / \mathrm{sec}, 100 \mu \mathrm{m})$ at the height of 90 $\mathrm{km}$ is shown in Fig.2. The ordinate is number ratio (log scale) of the recondensed grains to the evaporated gas molecules, and the abscissa is radius of the grain(on the top:number of atoms included in the grain). 
$\tau(0.1 \mathrm{sec})$ is time duration after the evaporation. It is clearly seen, that $10 \mathrm{sec}$ after the evaporation, radius is about $100 \mathrm{~A}$ and the ratio of the number density to the gas molecule is $10^{-10}$

We have to conclude that the secondary particles are very few and small compared with the primary meteorite by this calculation, in which the meteorite is very small (micrometeoroid). If the meteorite is large and fast enough, secondary particles would be important.

\section{Conclusion}

1) The comparison with the meteor stream observation from the ground is very interesting. Simultaneous observations from several points on the ground can determine the height and the velocity of a meteor stream:

a) Virginids $\quad 96 \mathrm{~km}>\mathrm{Z}>78 \mathrm{~km}, 30.8 \mathrm{~km} / \mathrm{sec}$

b) Capricornids $96 \mathrm{~km}>Z>86 \mathrm{~km}, 25.6 \mathrm{~km} / \mathrm{sec}$

These observations coincide almost exactly with our $(30 \mathrm{~km} / \mathrm{sec}$, $100 \mu \mathrm{m}$ ) particles.

2) It is guessed that the spherule's origin is "debris" of our calculation. The trouble is that spherules, collected in the deep sea bottom, have about $100 \mu \mathrm{m}$ size. It is conjectured that "sampling effect" is rather essential. If we can collect also small ones this inconsistency may be solved.

3) If the meteorite is $(20 \mathrm{~km} / \mathrm{sec}, 10 \mu \mathrm{m})$, heating is not much enough and it cannot reach the sublimation temperature, even if it is not fluffy. If the particle is fluffy, the heating is much smaller and it is quite natural that it is floating in the stratosphere in original shape.

4) The secondary particles are very few and small.

\section{Reference}

Onaka,T., Nakada,Y. and Kanijo,F. : Experiment on the Clustering of Fine Particles, Astrophys.\& Space Sci, 65,103(1978).

Figure captions are written precisely in the text. 

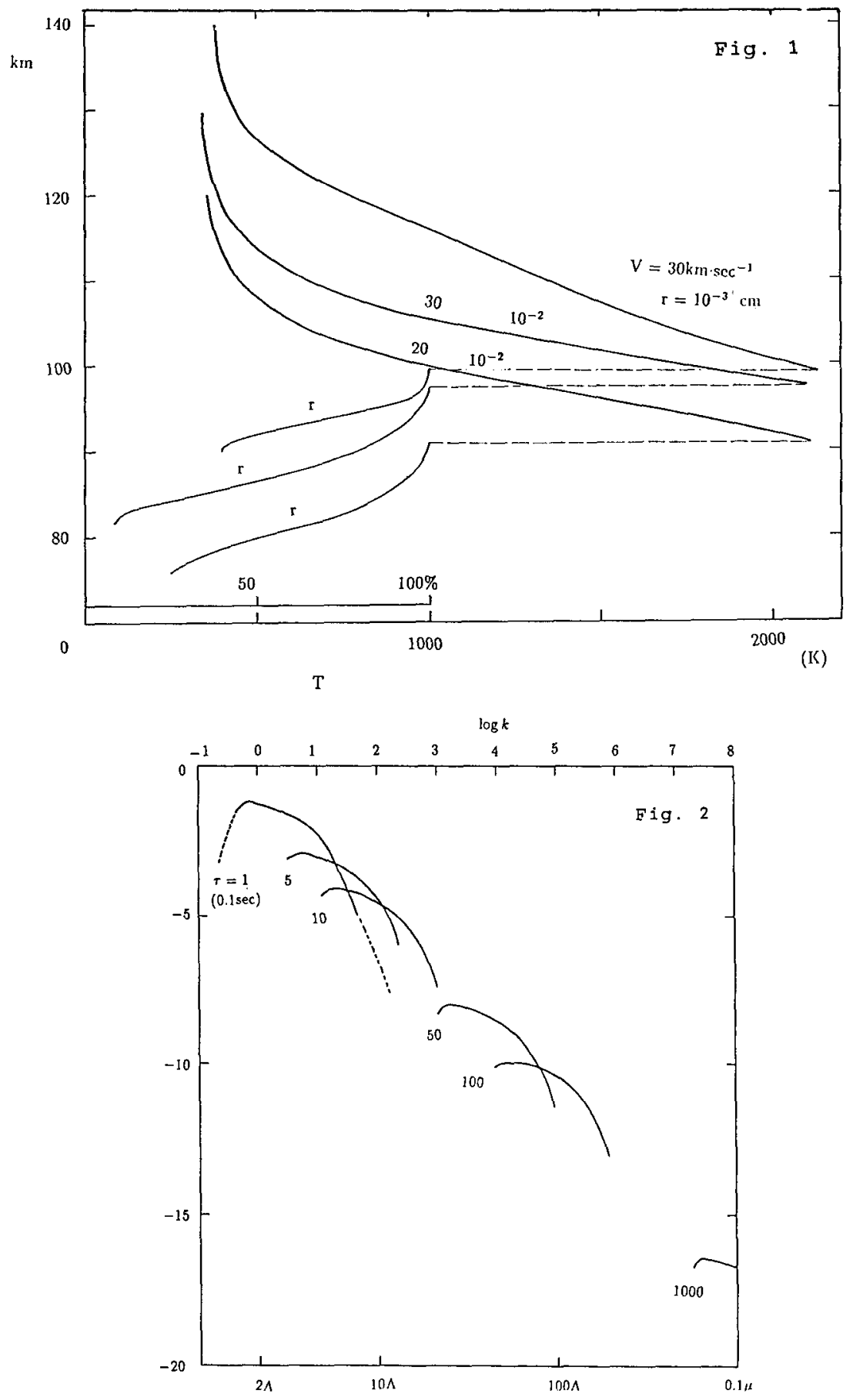